\title{
The Role of Carbon on Copper-Carbon Composites for the Electrooxidation of Alcohols in an Alkaline Medium
}

\author{
Leticia García-Cruz $^{1}$ (D), Conchi O. Ania ${ }^{2}$, Ana Paula Carvalho ${ }^{3}$, Teresa J. Bandosz ${ }^{4}$, \\ Vicente Montiel ${ }^{1}$ and Jesús Iniesta ${ }^{1, *}$ \\ 1 Department of Physical Chemistry and Institute of Electrochemistry, University of Alicante, \\ 03080 Alicante, Spain; leticia.garcia@ua.es (L.G.-C.); vicente.montiel@ua.es (V.M.) \\ 2 Conditions Extrêmes et Matériaux, Haute Température et Irradiation (CEMHTI) UPR 3079, \\ Le Centre National de la Recherche Scientifique (CNRS), Université d'Orléans, 45071 Orléans, France; \\ conchi.ania@cnrs-orleans.fr \\ 3 Departamento de Quimica, Universidade de Lisboa, 1749-016 Lisboa, Portugal; apcarvalho@fc.ul.pt \\ 4 Department of Chemistry and Biochemistry, The City College of New York, 160 Convent Avenue, \\ New York, NY 10031, USA; tbandosz@ccny.cuny.edu \\ * Correspondence: jesus.iniesta@ua.es; Tel.: +34-965-909-850
}

Received: 6 October 2017; Accepted: 15 November 2017; Published: 20 November 2017

\begin{abstract}
Copper-carbon composites were prepared following various different synthetic routes and using various carbon precursors (i.e., lignocellulose and graphite oxide), and were used as electrocatalysts for the oxidation of propargyl alcohol (PGA) in an alkaline medium. The electrochemical response of the copper-based catalysts was analyzed in terms of the influence of the metallic species, the carbon matrix incorporated in the composites, and the chemical structure of the ionomers-Nafion and poly (4-vinylpyridine) cross-linked methyl chloride quaternary salt resin (4VP)—used in the fabrication of the electrodes. Data has shown that the incorporation of reduced graphene oxide sheets between the copper metallic particles increased the performance due to the increased conductivity provided by the carbonaceous phase. Catalytic inks with ca. $40 \mathrm{wt} . \%$ Nafion and $12 \mathrm{wt} . \% 4 \mathrm{VP}$ as ionomers provided the best electrochemical response and cohesion of the catalysts, minimizing the losses in the electroactivity of the copper species.
\end{abstract}

Keywords: copper-based electrocatalysts; carbonaceous matrix; reduced graphene oxide; alkaline medium; alcohol electrooxidation

\section{Introduction}

Nanoparticulate systems based on non-precious metals are being widely used as an alternative to often low-performing and high-cost noble metals in the different research fields of electrochemistry [1-5]. Beyond their low cost and availability, transition metals exhibit high catalytic activities and coulombic efficiencies in a plethora of electrochemical processes where they are employed, with nickel, copper and cobalt, among others, being the most representative. Particular emphasis is placed on the use of copper due to its rich redox chemistry, with multiple reductive and oxidative reactions catalyzed by different copper complexes and oxides obtained as a function of applied electric potential; i.e., the reduction of $\mathrm{Cu}(\mathrm{II})$ species to either $\mathrm{Cu}(\mathrm{I})$ or $\mathrm{Cu}(0)$ species, and then the oxidation to $\mathrm{Cu}$ (II) or $\mathrm{Cu}(\mathrm{III})$, which in some cases are redox species with limited solubility in alkaline media [6-10]. Several works have shown copper-based electrodes as active catalysts in multiple processes such as electroanalysis and sensors [11-14], electrooxidation of small organic molecules $[15,16]$, fuel cells [14,17], organic electrosynthesis [18], water oxidation [19,20] and hydrogen evolution [20,21]. Besides, polycrystalline copper electrodes and $\mathrm{Cu}(0)$ nanoparticles, and even copper alloys-based 
electrodes, have exhibited high performance for hydrocarbon and alcohol synthesis directly from $\mathrm{CO}_{2}$ electroreduction [22-26], as they are the reaction mechanisms strongly sensitive to a local $\mathrm{pH}$ value, electrolyte concentration, particle size, electrode composition and surface structure [27-29]. Moreover, the copper-based electrodes display a stable and sensitive electrocatalytic response for carbohydrate oxidations, amino acids, amines, and primary and secondary alcohols, among others [30,31]. Many of the electrooxidation processes occur at high potentials, similar to the electrochemical potential of the $\mathrm{Cu}(\mathrm{II}) / \mathrm{Cu}$ (III) redox couple. In this regard, the $\mathrm{Cu}$ (III) species exists as a $\mathrm{CuOOH}$ stable crystalline form in the alkaline medium, and is then responsible for catalyzing, for instance, the electrooxidation of alcohols [15]. However, since copper species easily undergo corrosion at certain electrolytes [32], an important issue for improving the performance of copper-based materials is to control their size, shape and composition as well as their homogeneous dispersion on supplementary materials.

The use of metal nanoparticulate systems which are highly dispersed on varied carbon supports can offer important advantages in terms of electrode stability, conversion and the coulombic efficiency of their electrocatalytic activity [33-35]. The presence of adequate functional groups on the carbon material's surface allows, simultaneously, optimum anchoring and much stronger interactions of metallic nanoparticles, which improves both the dispersion and lifetime of the catalysts. Furthermore, the carbon support can modify the electronic character of non-precious metal nanoparticles, improving considerably the electrical conductivity, charge transfer and hence catalytic activity $[33,36]$. In this respect, extensive work is nowadays being devoted to the incorporation of highly conductive graphene or graphene-derived materials into such structures for their enhanced performance [37].

Based on previous studies on the electrocatalytic activity of nickel electrodes in the selective electrooxidation of primary alcohols in an alkaline medium [38], the main aim of the present work is to examine the electrocatalytic activity of copper nanoparticles supported on distinct carbon materials in the electrooxidation of propargyl alcohol (PGA) under alkaline conditions. Even though, as mentioned above, copper complexes and oxides are known to have strong catalytic activity in many oxidative and reductive reactions, the use of copper electrocatalysts is limited owing to a typical low reactivity [39] and corrosion [32] of such materials in certain electrolytes.

Knowing the capability of copper to promote oxidative reactions, and aiming to resolve the aforementioned drawbacks (low activity and stability), we have selected copper as a non-precious electrocatalytic metal. We have used copper-based catalysts obtained from the carbonization of two different carbon sources, graphite oxide (GO) and a biomass precursor, that provide two different carbon matrices. The catalysts prepared by the carbonization of a composite of a copper-containing metal organic framework (MOF) with GO have incorporated highly conductive sheets of reduced graphene oxide (formed during the carbonization on the composite), while the lignocellulosic precursor provides an amorphous carbon matrix with low electrical conductivity. The synthetic route also overcomes the usual problems encountered with the preparation of metal-doped carbons, regarding dispersion and aggregation of the metallic particles.

The technology of fuel cells involves the preparation of the nanoparticulate electrodes as well as gas-diffusion electrodes on to carbon structures, prompting the use of lower electrocatalyst loading and providing the same electrochemical performance. On this point, the ionomer nature and its composition within the catalytic layers play a crucial role during the electrochemical processes occurring inside the electrodes. Thus, we have explored the use of a cationic and an anionic ionomer in the preparation of the electrodes. Nafion is the cationic ionomer generally used as a binder in the inks used in polymer electrolyte membrane fuel cell devices. However, due to the increasing interest in direct alcohol fuel cells working in an alkaline medium, numerous studies have been directed towards the development of anionic ionomers that allow the transport of $\mathrm{OH}^{-}$ions through the catalytic layer of the electrodes [40]. The preparation and further electrochemical characterization of copper-based electrocatalysts with a high performance in electrochemical devices working under alkaline conditions would exhibit important benefits in terms of lower anode working potentials, fast reaction kinetics, and reduced electrocatalyst costs. 


\section{Results and Discussion}

A series of copper-carbon composites obtained using various precursors was prepared for use as anodes for the electrooxidation of propargyl alcohol in alkaline conditions, aimed at exploring the effect of the carbon matrix features and the copper loading and dispersion on the electrocatalytic activity of the anodes. The preparation and characterization of the samples obtained by carbonization of a composite of MOF and GO has been addressed in a previous study [37]. Here, we reintroduce some characteristics for the interpretation of the results then collected.

\subsection{Electrochemical Characterization of the Prepared Materials}

According to literature, the voltammetric response of the copper species in an alkaline medium is strongly dependent on the hydroxide concentration, potential sweep rates, and mass transport regime, among others [6]. Such variables may influence the formation of copper-derived passive films, e.g., copper hydroxide species achieved from oxidation-reduction processes [12]. Considering the complexity of the electrooxidation-reduction reaction mechanisms of the copper species, we first explored the electrochemical response of a copper rod in $0.1 \mathrm{M} \mathrm{NaOH}$ by means of cyclic voltammetry (Figure 1). The voltammograms showed a pattern of well-defined anodic and cathodic peaks corresponding to copper-based electrogenerated redox species, widely reported in the literature $[6,12,15,16]$. Briefly, Reaction (1) describes the oxidation of $\mathrm{Cu}(0)$ to $\mathrm{Cu}(\mathrm{I})$ redox species as denoted by peaks a1/c1.

$$
2 \mathrm{Cu}+2 \mathrm{OH}^{-} \rightarrow \mathrm{Cu}_{2} \mathrm{O}+\mathrm{H}_{2} \mathrm{O}+2 \mathrm{e}-
$$

The anodic peak a2 is associated with the formation of passivating copper oxide/hydroxide derivatives, as denoted by Reactions (2)-(4):

$$
\begin{gathered}
\mathrm{Cu}_{2} \mathrm{O}+2 \mathrm{OH}^{-} \rightarrow 2 \mathrm{CuO}+\mathrm{H}_{2} \mathrm{O}+2 \mathrm{e}- \\
\mathrm{Cu}+2 \mathrm{OH}^{-} \rightarrow \mathrm{CuO}+\mathrm{H}_{2} \mathrm{O}+2 \mathrm{e}- \\
\mathrm{Cu}+2 \mathrm{OH}^{-} \rightarrow \mathrm{Cu}(\mathrm{OH})_{2}+2 \mathrm{e}-
\end{gathered}
$$

According to [41], Reaction (5) is related to the formation of soluble species, as denoted by peak a2':

$$
\mathrm{Cu}+3 \mathrm{OH}^{-} \rightarrow \mathrm{HCuO}_{2}^{-}+\mathrm{H}_{2} \mathrm{O}+2 \mathrm{e}^{-}
$$

Most remarkably, the anodic peak potential associated with the electrooxidation of $\mathrm{Cu}$ (II) to $\mathrm{Cu}$ (III) species, i.e., $\mathrm{CuOOH}$ formation, appears at $0.590 \mathrm{~V}$ just before the water oxidation onset, which is ascribed to the anodic peak a3 (Reaction 6). Nevertheless, the anodic peak a3 under our experimental conditions was not well resolved as compared to other studies [15].

$$
\mathrm{CuO}+\mathrm{OH}^{-} \rightarrow \mathrm{CuOOH}+\mathrm{e}-
$$

(a3 Reaction 6)

The difficulty of the electroreduction of such copper oxide/hydroxide films is mainly attributed to the rather low conductivity of cuprous oxides [42]. Consequently, the cathodic peaks may undergo shifting of peak potentials associated with the reduction of $\mathrm{CuO} / \mathrm{Cu}(\mathrm{OH})_{2}$ to $\mathrm{Cu}_{2} \mathrm{O}$ and the reduction of $\mathrm{Cu}_{2} \mathrm{O}$ to $\mathrm{Cu}$, as a function of the experimental conditions such as electrolyte $[7,9,10]$ or the use of nanoparticulate copper electrodes (vide infra). 


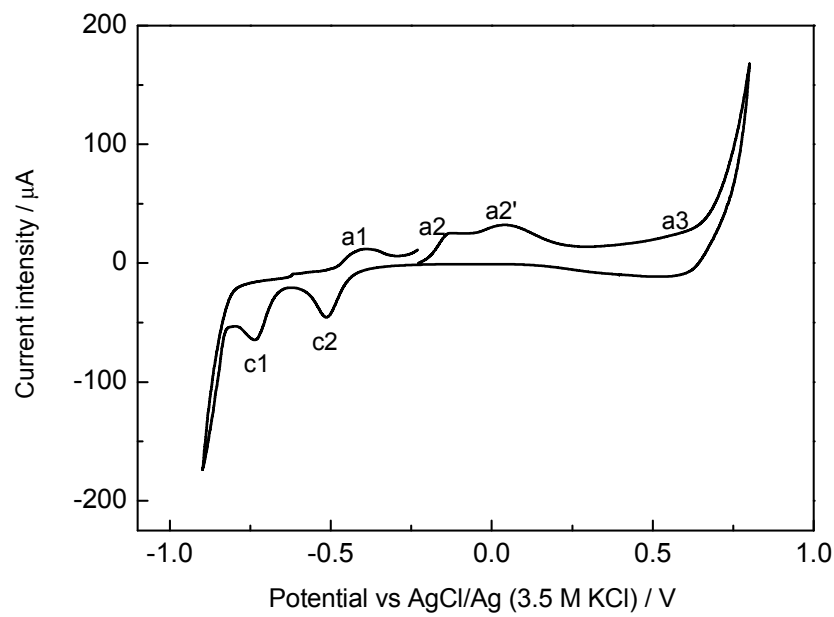

Figure 1. Cyclic voltammogram of the electrochemical response of the $\mathrm{Cu}$ rod electrode in $0.1 \mathrm{M} \mathrm{NaOH}$. First scan recorded. Scan rate $10 \mathrm{mV} \mathrm{s}^{-1}$.

Figure 2 depicts the electrochemical response of the synthesized copper-carbon electrodes in $0.1 \mathrm{M} \mathrm{NaOH}$; data corresponding to the undoped carbon obtained from the carbonization of the biomass precursor is also included for comparison.
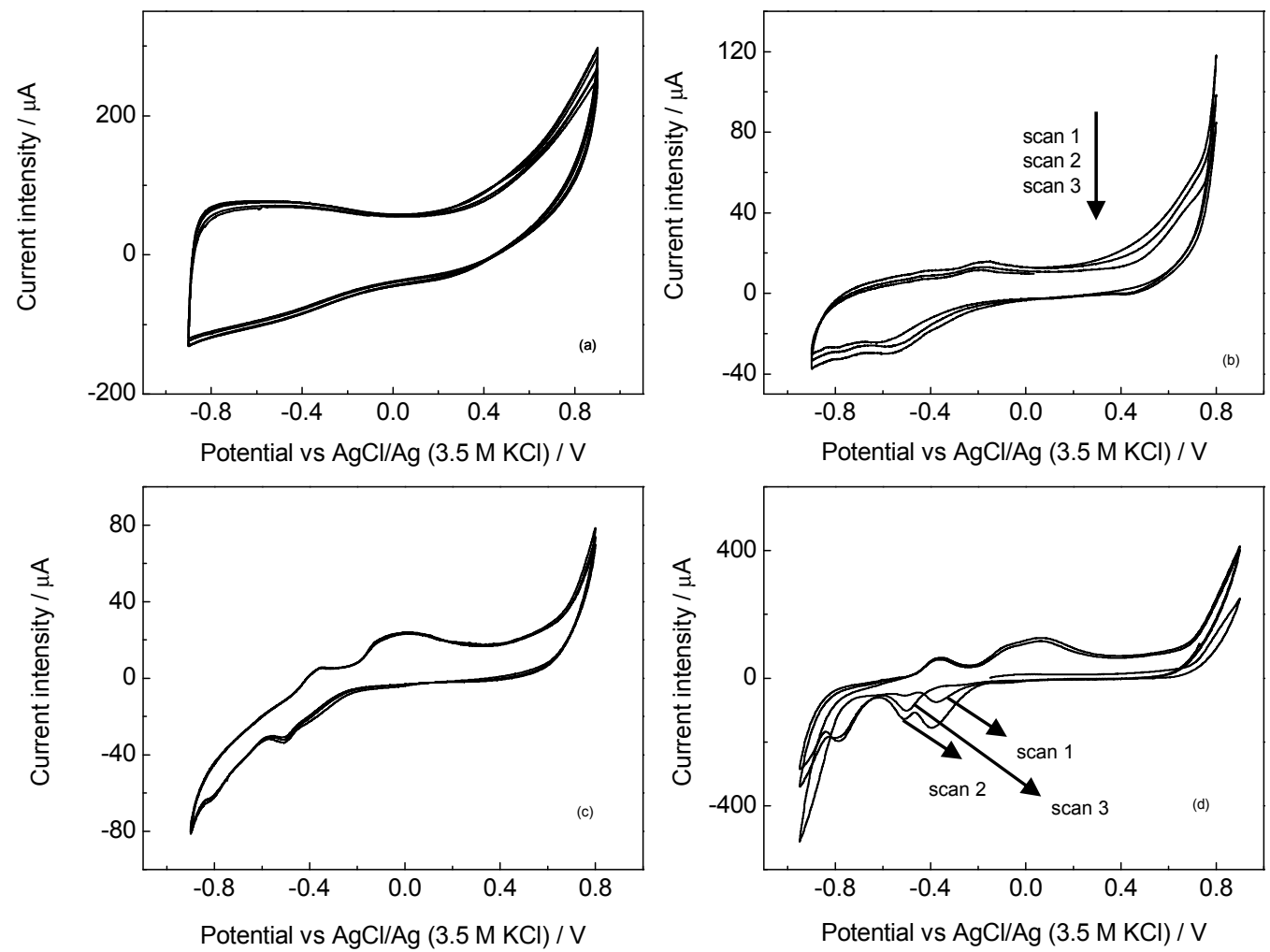

Figure 2. Cyclic voltammograms of the electrochemical response of (a) Nafion/S; (b) Nafion/SCu; (c) Nafion/CMCu; and (d) Nafion/CMCuGr in $0.1 \mathrm{M} \mathrm{NaOH}$. 40 wt. $\%$ Nafion ionomer in the catalytic inks. Scan rate $10 \mathrm{mV} \mathrm{s}^{-1}$. Three scans recorded.

As seen, the undoped carbon electrode displayed a pseudo-rectangular shape due to the dominant contribution of a capacitive intensity (ic), which is in agreement with its textural features (Table 1). Such a capacitive intensity decreased significantly for all the copper-carbon electrodes, as expected 
from their low porosity. The high porosity of the undoped sample $\mathrm{S}$ (ca. $970 \mathrm{~m}^{2} / \mathrm{g}$ ) compared to SCu (ca. $26 \mathrm{~m}^{2} / \mathrm{g}$ ) is reasonable, since $\mathrm{S}$ was obtained by impregnation of the lignocellulosic precursor with $\mathrm{Na}_{2} \mathrm{CO}_{3}$ (as opposed to $\mathrm{CuCO}_{3}$ for $\mathrm{SCu}$ ). Indeed, sodium carbonate is a well-known chemical activation agent used in the preparation of a large surface area of nanoporous carbons [43].

Table 1. Main textural parameters of the synthesized materials obtained from gas adsorption data.

\begin{tabular}{ccccc}
\hline Sample & $\mathrm{S}_{\text {BET }}\left(\mathbf{m}^{\mathbf{2}} / \mathbf{g}\right)$ & $\mathbf{V}_{\text {PORES }}{ }^{\mathbf{A}}\left(\mathrm{cm}^{3} / \mathbf{g}\right)$ & $\mathbf{V}_{\text {MIC }}{ }^{\mathbf{B}}\left(\mathrm{cm}^{3} / \mathbf{g}\right)$ & $\mathbf{p H}$ \\
\hline $\mathrm{S}$ & 970 & 0.45 & 0.41 & 8.3 \\
$\mathrm{SCu}$ & 26 & 0.07 & 0.01 & 8.2 \\
$\mathrm{CMCu}$ & 117 & 0.14 & 0.06 & 8.2 \\
$\mathrm{CMCuGr}$ & 53 & 0.10 & 0.03 & 7.7 \\
\hline
\end{tabular}

A Total pore volume evaluated at relative pressure 0.99 . ${ }^{B}$ Micropore volume evaluated by the Dubinin-Radushkevich method.

The lower porosity of sample SCu is clearly seen in the lower capacitive intensity of the electrochemical pattern in Figure 2. The ill-defined and broad waves assigned to the pair c2/a2 were also detected in the electrochemical pattern of SCu. The cathodic $\mathrm{c} 2$ peak became less intense and shifted towards more negative potentials with scanning, becoming stable after the third scan. This decrease in intensity is likely caused by a partial formation of passivated copper species on the copper nanoparticles due to strong local alkaline $\mathrm{pH}$ near the $\mathrm{Cu}$ surface [42].

On the contrary, the peaks corresponding to the redox transitions of the different copper species were clearly visible for $\mathrm{CMCu}$ and $\mathrm{CMCuGr}$ samples and also the capacity currents obtained for them are in agreement with their isotherms shown in Table 1.

The low intensity of the waves attributed to copper species in SCu carbon contrasts with the relatively large amount of copper of this material (ca. $56 \mathrm{wt} . \%$ ) according to the synthesis procedure and the ash content (ca. 57 and $3 \mathrm{wt} . \%$ for SCu and S, respectively), of about the same order of magnitude as that of $\mathrm{CMCuGr}$ and $\mathrm{CMCu}$ (ca. 92 and $57 \mathrm{wt} . \%$ for $\mathrm{CMCu}$ and $\mathrm{CMCuGr}$, respectively). This suggests that the copper is in the different form. The intensities of the electrochemical peaks of the $\mathrm{CMCu}$ sample were significantly lower than those of the $\mathrm{CMCuGr}$ sample (despite the higher copper loading), with a much more resistive electrochemical pattern (particularly reduction peaks c2 and $\mathrm{c} 1$ ). Hence, the electrochemical response of $\mathrm{CMCu}$ seems to be dominated by low conductivity [37]. On the contrary, the $\mathrm{CMCuGr}$ sample displayed higher current intensities and a better resolution of oxidation-reduction peaks. This likely indicates favorable interactions between copper nanoparticles and the graphene-like sheets, avoiding copper passivation and enhancing electron transfer [39].

To further explore the chemical nature of the copper present on the different copper-carbon electrodes, X-ray photoelectron spectroscopy (XPS) analysis was performed. Data of the surface atomic concentration of elements is compiled in Table 2.

Table 2. Concentration (\%) of elements on the surface of the catalysts determined by X-ray photoelectron spectroscopy (XPS).

\begin{tabular}{cccc}
\hline Sample & C 1s & O 1s & Cu 2p \\
\hline S & 87.0 & 13.4 & n.d. \\
SCu & 69.4 & 12.6 & 18.5 \\
$\mathrm{CMCu}$ & 90.86 & 7.40 & 1.75 \\
$\mathrm{CMCuGr}$ & 94.65 & 4.58 & 0.77 \\
\hline
\end{tabular}

For all samples, XPS spectra show a main Cu 2p3/2 signal composed of two contributions at $932.9 \mathrm{eV}$ and $935.2 \mathrm{eV}$, assigned to $\mathrm{Cu}(0)$ and $\mathrm{Cu}(\mathrm{II})$, respectively (Figure $\mathrm{S1}$ ). The ratio of the areas of the satellite region (ca. 940-945 eV) to the main Cu 2p3/2 signal (ca. 932-940 eV) is an indication of the oxidation state of the copper species, being 0.55 when only $\mathrm{Cu}$ (II) species are present. In our samples, 
the ratios were $0.54,0.36$ and 0.33 for $\mathrm{SCu}, \mathrm{CMCuGr}$ and $\mathrm{CMCu}$, respectively, indicating a high reduction degree of copper for $\mathrm{CMCuGr}$ and $\mathrm{CMCu}$, compared to $\mathrm{SCu}$. This is further confirmed by the deconvolution of the $\mathrm{Cu} 2 \mathrm{p} 3 / 2$ signals, where the small peak at $932.9 \mathrm{eV}$ (accounting for $3 \%$ ) for the SCu sample suggests that the surface contribution of reduced copper is low.

The analysis of the speciation of oxygen and carbon groups obtained from the deconvolution of the $\mathrm{C} 1 \mathrm{~s}$ and $\mathrm{O} 1 \mathrm{~s}$ core-level spectra is shown in Figure 3.
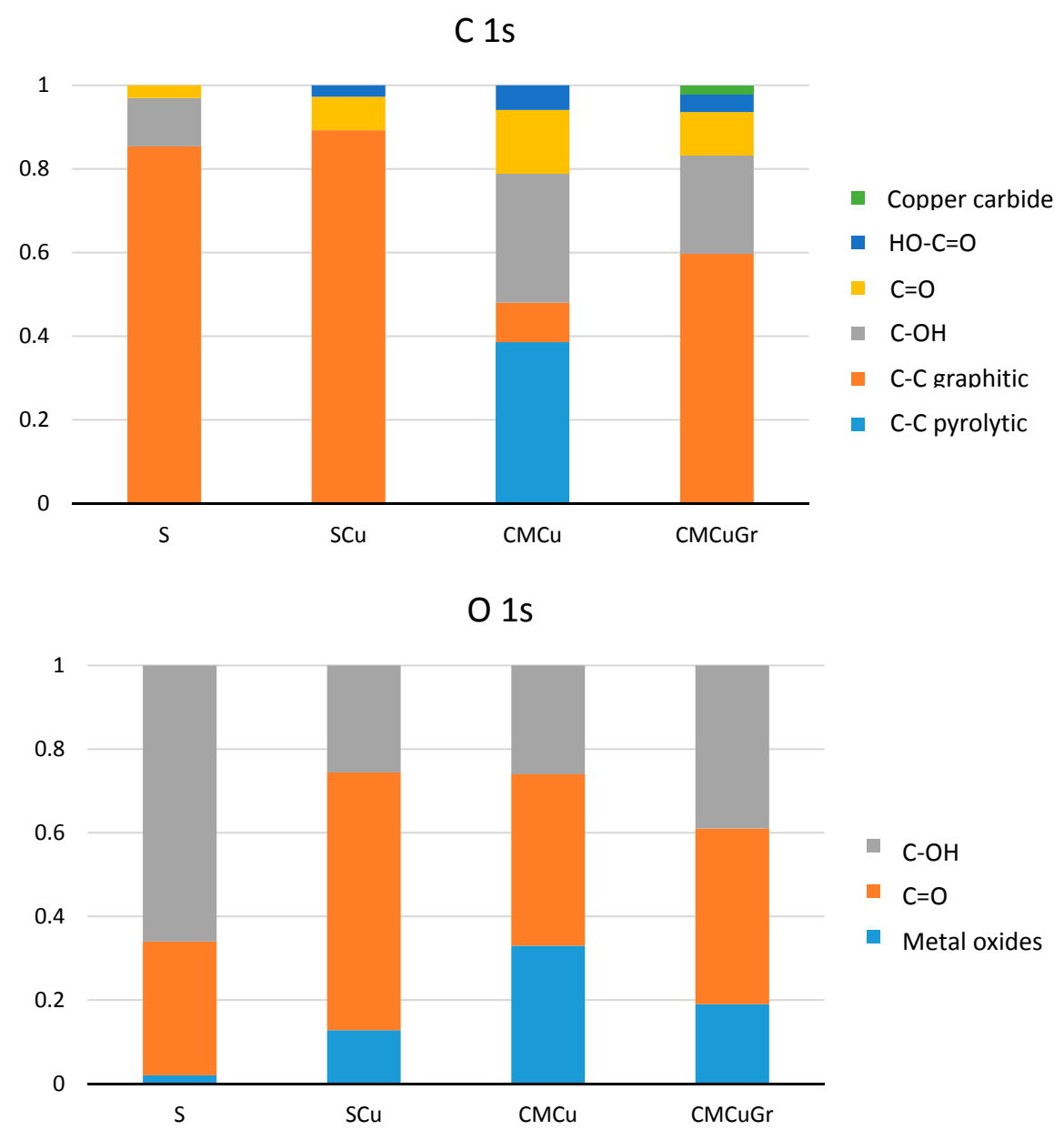

Figure 3. Relative distribution of surface functional groups identified by XPS.

As seen, all samples showed relatively large amounts of oxygen, with the lowest value for $\mathrm{CMCuGr}$, indicating that the surface of the materials has some degree of oxidation and that oxygen is associated to copper. However, in the case of the biomass-derived catalysts (samples SCu and S), the undoped material also displays a large oxygen content, suggesting that its oxygen is mainly associated to the carbonaceous matrix. The SCu sample also shows a much higher amount of copper on the surface than do the $\mathrm{CMCu}$ and $\mathrm{CMCuGr}$ samples, suggesting a surface aggregation of the metallic particles. This is in agreement with the differences in morphology and topology observed in the field emission scanning electron microscopy (FESEM) and transmission electron microscopy (TEM) images (Figure 4 and Figure S2). The image of the composite prepared by the impregnation of the lignocellulosic precursor with a copper salt (sample $\mathrm{SCu}$ ) displayed highly aggregated copper species, as well as some dark particles owing to the presence of the carbon matrix (similar to that of the undoped sample $S$ ). In the composites prepared by the carbonization of the MOF (both in the presence and absence of GO), the copper particles have a globular morphology. The corrugated graphene-like layers can also be observed in the CMCuGr sample, covered with copper particles. 


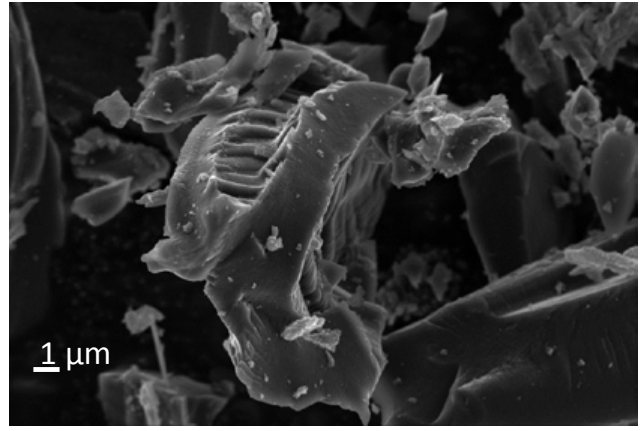

(a)

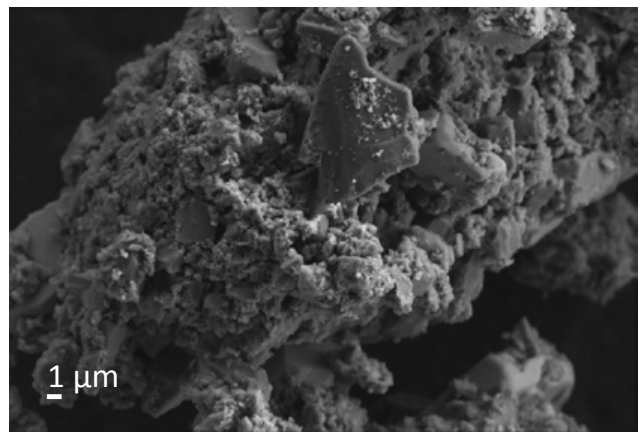

(c)

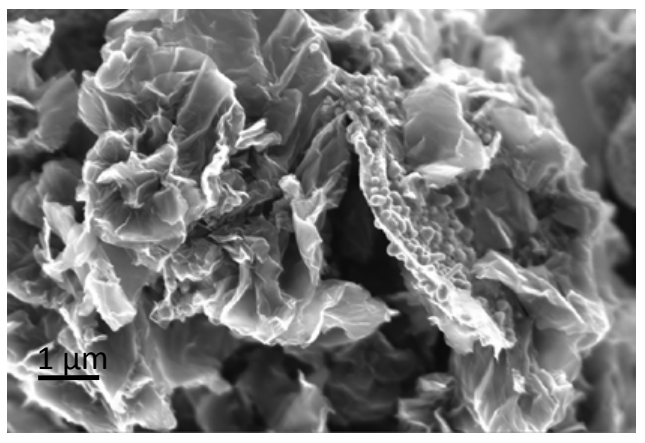

(e)

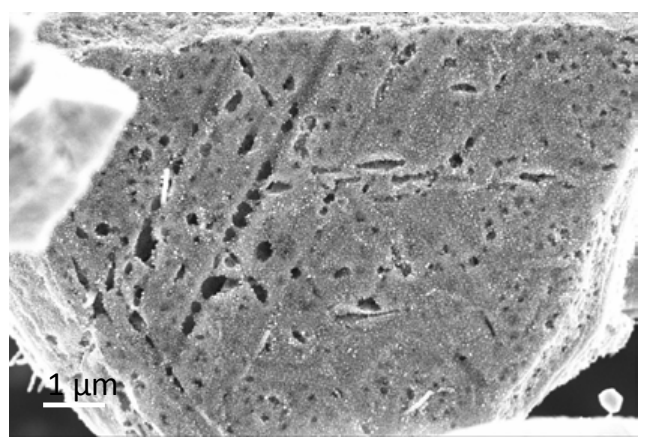

(g)

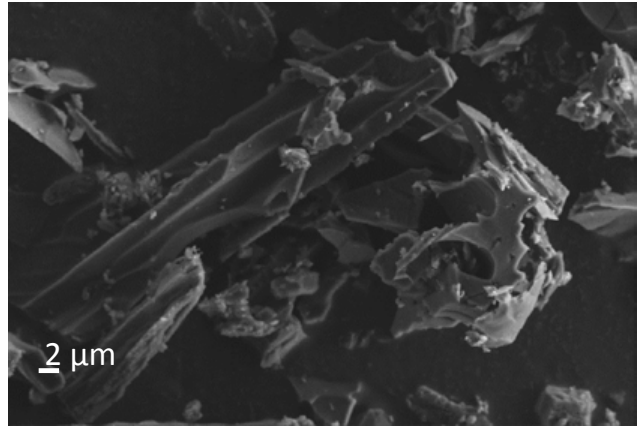

(b)

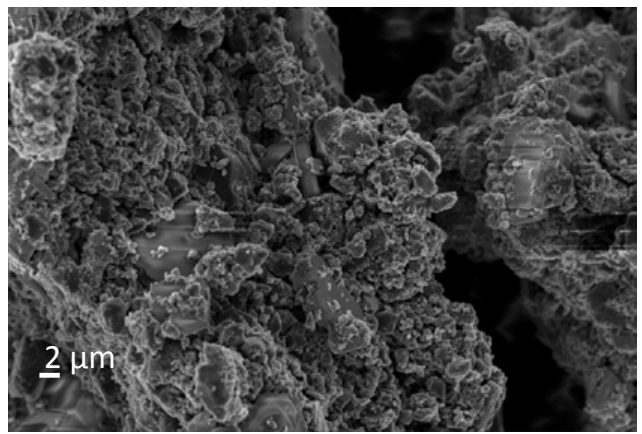

(d)

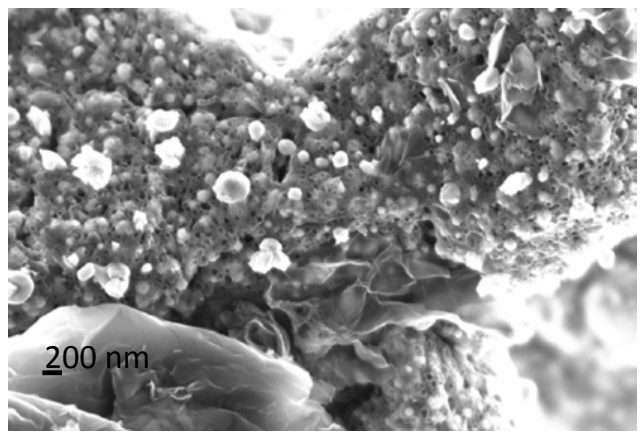

(f)

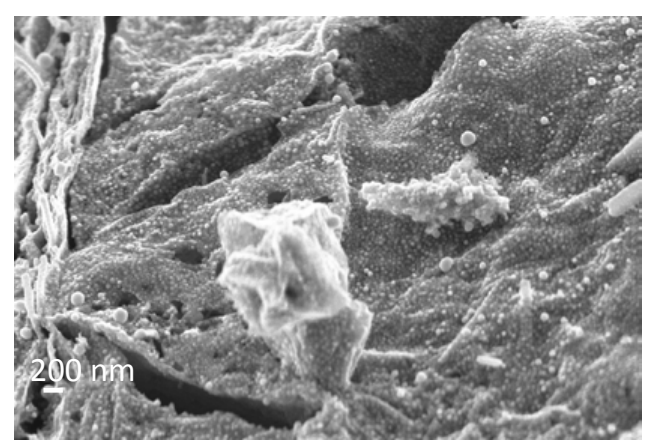

(h)

Figure 4. Representative field emission scanning electron microscopy (FESEM) images of the $S$ (a,b); $\mathrm{SCu}(\mathbf{c}, \mathbf{d}) ; \mathrm{CMCuGr}(\mathbf{e}, \mathbf{f})$; and CMCu (g,h) samples. 
Concerning a relative distribution of surface functional groups, the $C$ 1s core-level spectra of the studied samples revealed differences in the chemistry of the carbon matrix. Whereas for S, SCu and $\mathrm{CMCuGr}$, the carbon is predominantly in a graphitic form, sample $\mathrm{CMCu}$ reveals a relatively large contribution of pyrolytic carbon (ca. $284.3 \mathrm{eV}$ ), as shown in Figure 3. This is in agreement with the amorphous carbon phase observed in the TEM images, and it is linked to the decomposition of the organic linkers of the MOF used as the precursor.

Conversely, the graphitic carbon in the $\mathrm{CMCuGr}$ originates from the GO incorporated in the precursor. This is expected to influence the electron transfer in the electrocatalysts, since graphitic carbon is a conducting material compared to pyrolytic carbon. In addition, the samples exhibit similar distributions of carbon atoms in various oxygen environments (accounting for carbonyl, carbonates or carboxylic groups). This was further confirmed by the $\mathrm{O} 1 \mathrm{~s}$ core-level signals; the broad peaks were decomposed in three contributions at $530.8 \mathrm{eV}, 531.7 \mathrm{eV}$, and $533.5-533.8 \mathrm{eV}$, assigned to oxygen from metal oxides, carbonyl/carboxyl and phenol groups, respectively. In the case of $\mathrm{CMCuGr}$, a small peak at $282.4 \mathrm{eV}$ was assigned to the presence of copper carbide.

\subsection{Electrocatalytic Oxidation of Propargylic Alcohol}

The electrooxidation of primary unsaturated alcohols such as PGA in alkaline conditions was initially investigated at a copper rod electrode. Figure 5a displays the CV response of this electrode material in the presence of 0.02 M PGA. An increase in the intensity at high anodic potential confirmed the oxidation of the unsaturated alcohol through a mediated electron transfer mechanism catalyzed by the $\mathrm{CuOOH}$ electroactive species; these were formed during the positive scan at high potential before the onset of water decomposition (peak a3 in Figure 1). Consequently, the increased current intensity in the anodic wave at $0.670 \mathrm{~V}$ (due to the oxidation of PGA) is accompanied by a significant decrease in the intensities of the cathodic peaks $\mathrm{c} 1$ and $\mathrm{c} 2$, as well as the anodic a1 peak. Moreover, the anodic peaks a1 and a2 are shifted to more positive potentials of about -310 and $130 \mathrm{mV}$, respectively. Similar electrochemical behavior has been reported for the electrooxidation of methanol and cyclohexanol at copper electrodes in alkaline conditions [15-17].
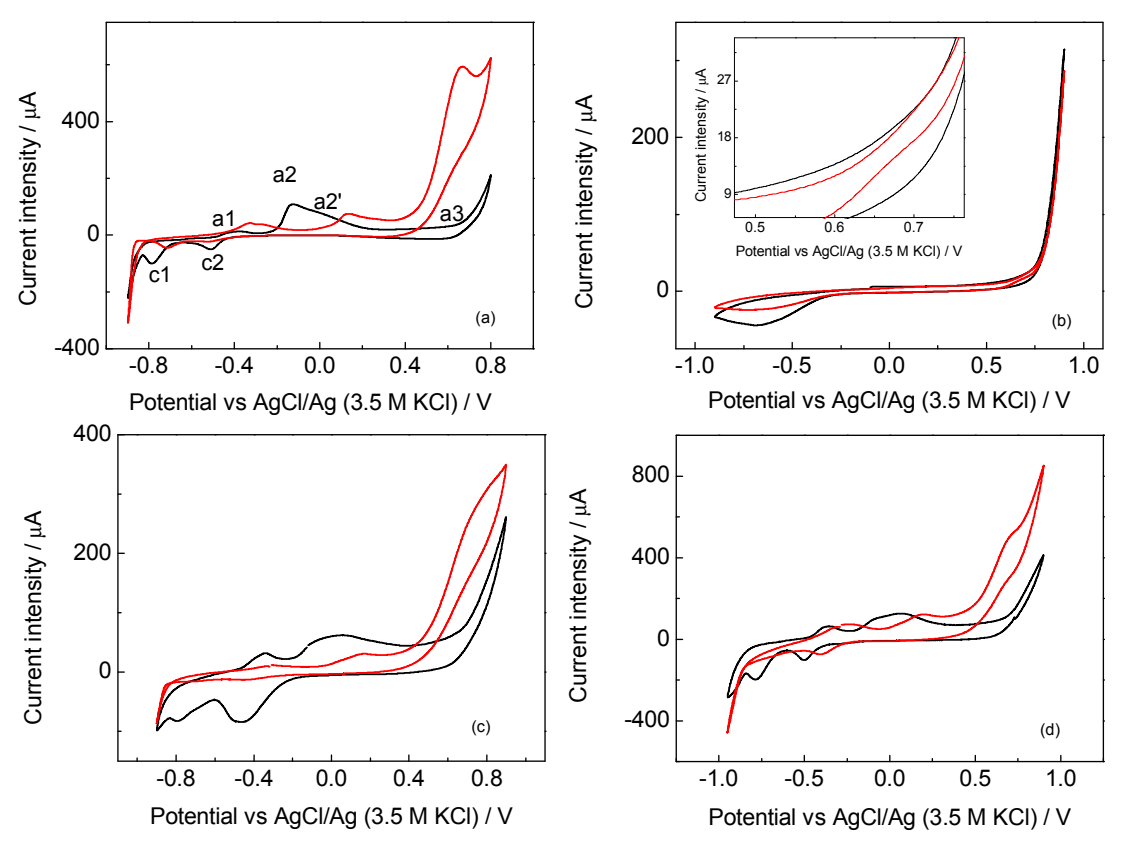

Figure 5. Cyclic voltammograms of the electrochemical response of the (a) $\mathrm{Cu}$ rod; (b) Nafion/SCu; (c) Nafion/CMCu; and (d) Nafion/CMCuGr in $0.1 \mathrm{M} \mathrm{NaOH}$ (black line) and in the presence of 0.02 M PGA (red line). $40 \mathrm{wt}$ \% Nafion ionomer in the catalytic inks. Third scan recorded. Scan rate $10 \mathrm{mV} \mathrm{s}^{-1}$. Inset figure: $\mathrm{SCu}$ voltammogram ranges from $0.3 \mathrm{~V}$ to $0.8 \mathrm{~V}$, positive scan direction. 
Adsorption of unsaturated alcohols likely takes place on copper species of low valence state and it is further oxidized via the participation of $\mathrm{Cu}$ (III) species at a high potential (peak a3) parallel to $\mathrm{CuOOH}$ formation from $\mathrm{Cu}$ (II). The nature of adsorption of unsaturated alcohols involves the formation of a hapto-propiolate complex to the copper (III) species via the triple bond of the alkyne moiety $[38,44]$. The appearance of an anodic peak at $650 \mathrm{mV}$ observed on the reverse scan indicates that PGA electrooxidation goes on simultaneously with the electroregeneration of the $\mathrm{Cu}(\mathrm{III})$ from $\mathrm{Cu}$ (II) after water oxidation. This catalytic behavior is clearly observed by means of a concentration study $[15,17,38]$. It is noteworthy that the electrooxidation of 0.02 M PGA was reproducible with an increasing number of scans.

The electrocatalytic response of the studied copper-carbon materials in the presence of $0.02 \mathrm{M}$ PGA in an alkaline medium is shown in Figure $5 b-d$. No anodic wave was detected for the oxidation of PGA upon the positive scan using samples of undoped S carbon (Figure S3) and SCu (Figure 5b and inset figure). However, for the SCu carbon sample, a slightly lower intensity anodic wave at ca. $0.680 \mathrm{~V}$ on the reverse scan can be noted due to the reactivation of the copper surface, and is indirectly associated to the oxidation of PGA occurring by water oxidation. In contrast, the presence of $0.02 \mathrm{M}$ PGA resulted in an oxidation wave at a peak potential of $0.710 \mathrm{~V}$ vs. $\mathrm{AgCl} / \mathrm{Ag}$ when using the $\mathrm{CMCuGr}$ carbon as the electrode. Similarly, for $\mathrm{CMCu}$ an anodic shoulder near $+0.700 \mathrm{~V}$ is observed (Figure $5 c, d$ ). The presence of PGA also resulted in a significant positive shift in the position of a1 and a2 peaks. Generally, the redox processes associated with $\mathrm{c} 2$ and $\mathrm{c} 1$ of the peak potentials -0.500 and $-0.790 \mathrm{~V}$, respectively, almost or partially disappeared in the presence of the alcohol as a consequence of regeneration of $\mathrm{Cu}(\mathrm{III})$ species at ca. $0.690 \mathrm{~V}$ after alcohol and water oxidation. Nevertheless, peak intensity resulting from the PGA electrooxidation as well as the overall cyclic voltammetry profile is stable and reproducible with an increasing number of scans for all copper-containing carbon samples, hence demonstrating a good electrochemical stability of our copper-based carbon materials under cited experimental conditions.

The different electrochemical behavior of Figure $5 \mathrm{a}-\mathrm{d}$ is probably related to the incorporation of metal particles in the porosity and dispersion of the active metallic species in terms of possibly fewer aggregation events of copper particles into different carbon matrices, rather than overall copper content along with the poor conductivity of the carbon matrix (ca. mainly amorphous carbon phase). The lack of an anodic oxidation wave for the SCu sample during a positive scan, despite the large amount of copper in this sample (Table 2), and the speciation of copper species obtained from XPS analysis, may be attributed to the formation of metallic aggregates clearly observed in the FESEM images above, leading to most of the copper species of this material being not active or correctly exposed on the surface for the electrooxidation reaction. On the other hand, the intensity associated with the PGA electrooxidation in CMGrCu was almost two times higher than that of $\mathrm{CMCu}$, despite the larger copper content of the latter. Copper oxides and hydroxides are poorly conductive, so the electron transfer kinetic is dominated by the passage of the electrons from the carbon substrate to the copper nanoparticulate system. The presence of a two-dimensional network like graphene sheets facilitates electrons moving freely in the network and will promote more easily supplied electrons to the copper nanoparticulate systems, or vice versa, for the amelioration of the electron transfer kinetic and, consequently, to withdraw electrons from the PGA molecule. This is not the case for the $\mathrm{CMCu}$ sample where the carbon substrate presents mostly a $\mathrm{C}-\mathrm{C}$ pyrolytic structure compared to the carbon atoms $\mathrm{sp}^{2}$ bonds exhibited in graphene. Therefore, the electroactivity of the copper species (also present in $\mathrm{CMCu}$ ) does not provide an efficient electrode material; the graphene-like phase of $\mathrm{CMCuGr}$ would be crucial for allowing an effective coupling of electroactive copper species dispersed within the conductive graphene-based phase (dominant in $\mathrm{CMCuGr}$ ).

\subsection{Effect of the Ionomer}

We have also investigated the influence of an anionic ionomer (i.e., 4 -vinyl pyridine quaternary salt, $4 \mathrm{VP}$ ) [45] on the electrochemical response. Initial tests for optimizing the concentration of the ionomer in $0.1 \mathrm{M} \mathrm{NaOH}$ were carried out on the best-performing electrode material: $\mathrm{CMCuGr}$ carbon (based on 
its highly electroactive copper loading, and low electric resistivity). Figure 6 shows that increasing the 4VP content in the catalytic ink resulted in a decrease in the electrocatalytic activity of the electrode, most likely due to blockage of the electroactive copper surface, leading to high electron resistance. Indeed, an increase in the amount of 4VP resulted in ill-defined electrochemical patterns of $\mathrm{CMCuGr}$ in $0.1 \mathrm{M} \mathrm{NaOH}$, with notably less resolved peaks and lower intensities-attributed to copper redox processes-than those obtained with the Nafion ionomer (Figure 2d). Furthermore, the peak $\mathrm{c} 1$ is shifted to more positive potentials. Interestingly, at lower and intermediate $4 \mathrm{VP}$ content, an anodic wave is resolved at a peak potential near $0.5 \mathrm{~V}$ and it is linked to Reaction 6.

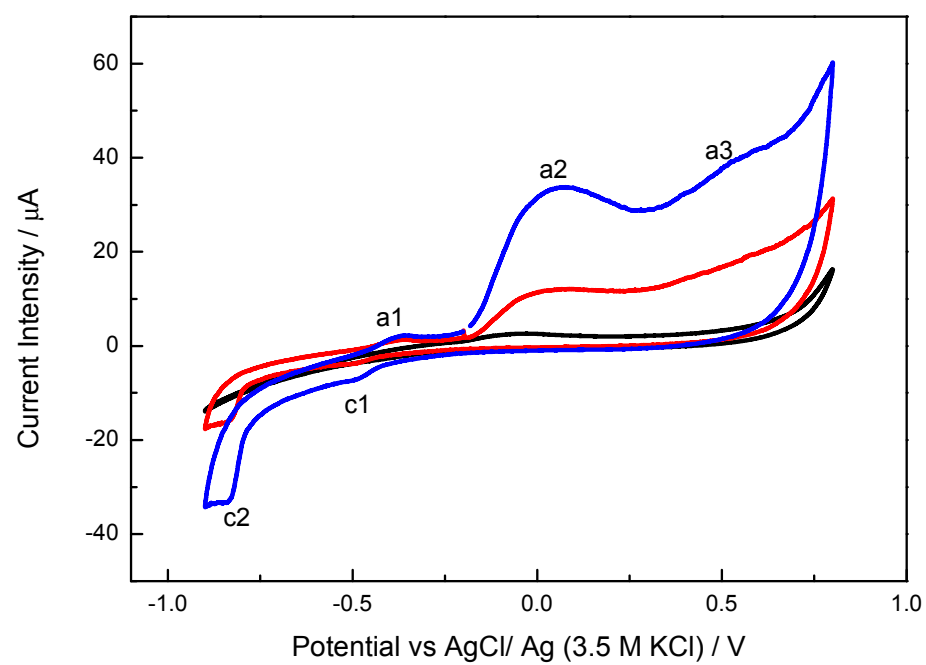

Figure 6. Cyclic voltammograms of the electrochemical response of the CMCuGr sample with a different content of $4 \mathrm{VP}$ of 7 (blue line), 12 (red line), and $20 \mathrm{wt}$ \% (black line) cast on to a glassy carbon electrode (GCE) in $0.1 \mathrm{M} \mathrm{NaOH}$. Scan rate $10 \mathrm{mV} \mathrm{s}^{-1}$. Third scan recorded.

On the other hand, the adhesion of the film onto a glassy carbon substrate and the mechanical properties of the electrodes were improved with increasing amounts of the ionomer; $12 \mathrm{wt} . \%$ and $20 \mathrm{wt} . \% 4 \mathrm{VP}$ provided a good cohesion between the copper/carbon composite particles and the glassy carbon electrode's underlying surface. From a mechanical point of view, $20 \mathrm{wt}$. $\%$ turned out to be the optimum $4 \mathrm{VP}$ ionomer amount, although the electrochemical pattern of the electrode was lost. Similar results have been reported for the preparation of catalytic layers of gas-diffusion electrodes based on platinum nanoparticles containing 4VP ionomer, whose structure is also described in [46]. Note that $4 \mathrm{VP}$ resin presents pyridine groups whose nitrogen atoms can lead to the formation of strong interactions with copper nanoparticles, thereby provoking the fouling or blockage of the catalytic surface along with the detriment of the electrochemical response. The porosity of the carbon materials with copper content can be modified in the presence of binders as a function of its structures, which is the origin of the different electrochemical performance of the catalytic inks.

Based on the compromise between a good electrochemical response and electrode cohesion, $12 \mathrm{wt} . \% 4 \mathrm{VP}$ was chosen for the preparation of $4 \mathrm{VP} / \mathrm{CMCu}, 4 \mathrm{VP} / \mathrm{CMCuGr}$, and $4 \mathrm{VP} / \mathrm{SCu}$ electrodes, to investigate the effect on the electrooxidation of PGA in an alkaline medium.

The cyclic voltammogram of $4 \mathrm{VP} / \mathrm{CMCu}$ electrode (Figure $7 \mathrm{a}$ ) in the absence of PGA clearly indicates a higher resistance compared to those of $4 \mathrm{VP} / \mathrm{CMCuGr}$ (Figure $7 \mathrm{~b}$ ) and $4 \mathrm{VP} / \mathrm{SCu}$ (Figure 7c) electrodes. This suggests a limited charge transport through the anionic ionomer. Also, the electrochemical behavior of copper under alkaline conditions is lost. Strikingly, the presence of $0.02 \mathrm{M}$ PGA results in a stable anodic peak although at a more positive potential—of ca. $+0.850 \mathrm{~V} —$ compared to that obtained for its counterpart $\mathrm{CMCu}$ using Nafion as ionomer, a consequence of the presence of the resistive components of the electrodes. In addition, the $4 \mathrm{VP} / \mathrm{CMCu}$ electrode depicts an oxidation intensity for PGA about 
10 times higher than that obtained for $4 \mathrm{VP} / \mathrm{CMCuGr}$ (Figure $7 \mathrm{~b}$ ). This fact is likely attributable to higher copper loading in the $\mathrm{CMCu}$ material (Table 2) along with a certain blockage effect, for the presence of 4VP ionomer in the $\mathrm{CMCuGr}$ carbon structure hinders the electron moving in the network of graphene sheets and the accessibility of the alcohol molecule to the copper species.

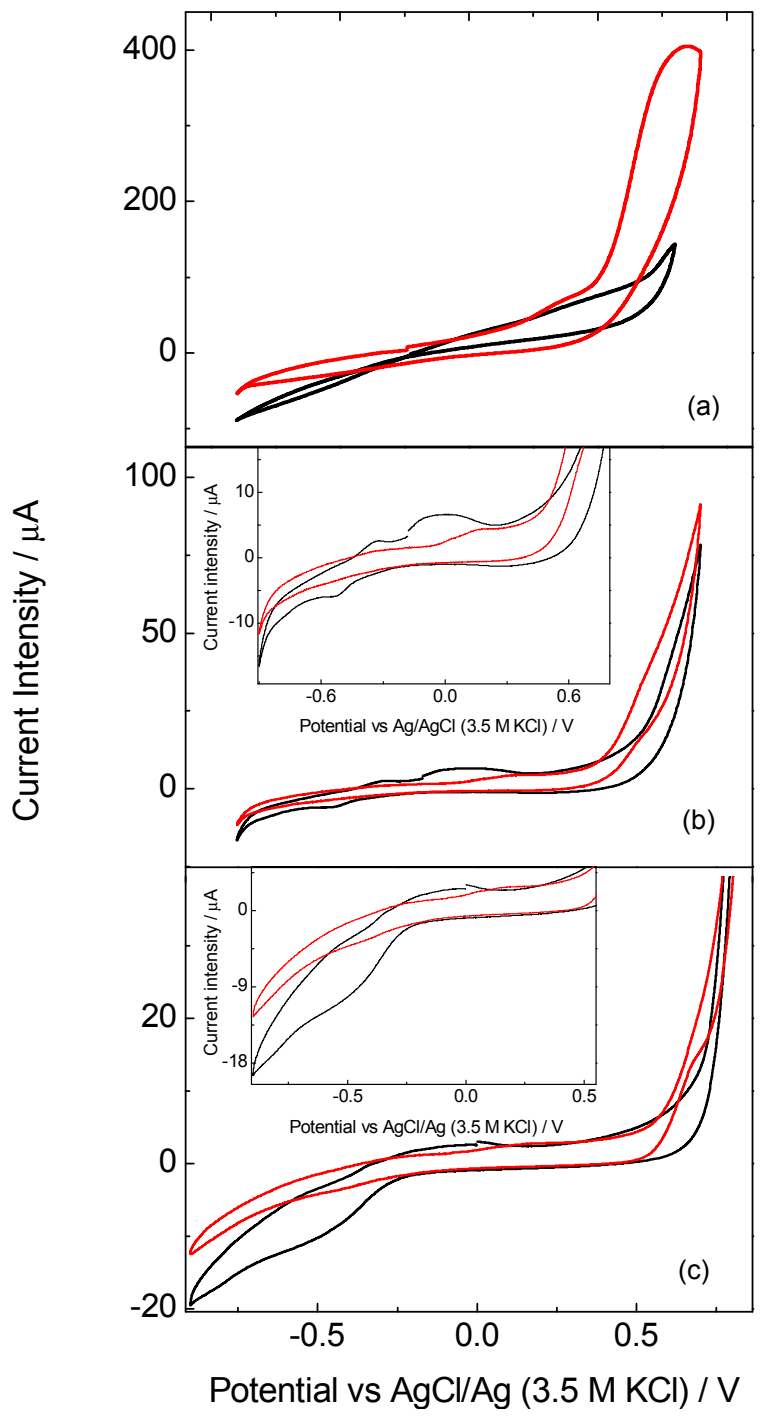

Figure 7. Cyclic voltammograms of the electrochemical response of (a) $4 \mathrm{VP} / \mathrm{CMCu}$; (b) $4 \mathrm{VP} / \mathrm{CMCuGr}$; and (c) $4 \mathrm{VP} / \mathrm{SCu}$ with $12 \mathrm{wt} . \% 4 \mathrm{VP}$ ionomer cast onto a GCE in the absence (black line) and presence of $0.02 \mathrm{M}$ PGA (red line) in $0.1 \mathrm{M} \mathrm{NaOH}$. Scan rate $10 \mathrm{mV} \mathrm{s}^{-1}$. Third scan recorded. Inset Figures: $4 \mathrm{VP} / \mathrm{CMCuGr}$ voltammogram ranges from $-0.8 \mathrm{~V}$ to $0.8 \mathrm{~V}$, and $4 \mathrm{VP} / \mathrm{SCu}$ voltammogram ranges from $-0.7 \mathrm{~V}$ to $0.5 \mathrm{~V}$ positive scan direction, respectively.

In the case of the $4 \mathrm{VP} / \mathrm{CMCuGr}$ electrode, the cathodic and anodic peak potentials of the voltammograms in the absence of the alcohol still agreed with those of the same electrode with Nafion as ionomer (inset in Figure $7 \mathrm{~b}$, black line). Additionally, it should be noted that the anodic peak corresponding to the PGA oxidation is ill-defined and takes place along with water oxidation. Moreover, the decrease in the current intensity of a2 and c1 peaks was observed as a result of PGA electrooxidation catalyzed by $\mathrm{CuOOH}$ species.

As far as the use of the SCu sample is concerned, the ionomer does not affect the response much in the absence of the alcohol, since similar electrochemical behaviors were obtained for $4 \mathrm{VP} / \mathrm{SCu}$ (Figure 7c, black line) and Nafion/SCu (Figure 5b, black line) electrodes. Anodic and cathodic redox 
processes involved in a2 and c2 peaks are observed in the absence of alcohol (inset in Figure 7c). The presence of 0.02 M PGA led to a significant decrease in the intensity of the cathodic peak c2, along with a notable increase in the intensity of that at ca. $0.650 \mathrm{~V}$. The positive effect on the alcohol electrooxidation when $4 \mathrm{VP}$ is used is not surprising, since despite $\mathrm{OH}^{-}$mobility through the catalytic layer being ensured because the electrode is completely immersed in $0.1 \mathrm{M} \mathrm{NaOH}$ solution, the presence of anionic resin can facilitate the mobility and transfer of hydroxide anions even more, favoring the electrochemical process. Thus, we conclude that the 4VP/SCu electrode exhibits an electrochemical behavior which is very similar to that of the $\mathrm{Cu}$ rod in terms of adsorption of the unsaturated alcohol and its electrooxidation via the participation of $\mathrm{Cu}(\mathrm{III})$ species.

A key point of this work is to indicate the balance between the electrocatalytic properties of the copper-carbon catalysts for the electrooxidation of PGA, and the adequate formulation of the catalytic ink to enhance the cohesion of the catalyst particles. Our findings suggest that the scale up of the electrooxidation of alcohols in alkaline media for organic electrosynthesis using copper-carbon catalysts is feasible in organic electrosynthesis. With regard to the electrooxidation of PGA using a divided electrolytic cell under controlled potential conditions, preliminary experiments have demonstrated the formation of a propiolic acid derivative, (Z)-3-(2-propynoxy)-2-propenoic acid as a unique product, via the participation of $\mathrm{Cu}$ (III) species, as was already demonstrated in a previous report using a nickel electrode under similar experimental conditions [38,44]. Such a product was also reported in the electrooxidation of PGA using $\mathrm{Ni}$ and $\mathrm{Ni}$-carbon nanoparticulated electrodes under alkaline conditions [38,44]. Based on results on the electroactivity of copper-carbon catalysts in the oxidation of PGA that have been obtained, additional lab- and bench-scale studies are encouraged using large electrode sizes and various electrochemical cell configurations (e.g., filter-press reactors). Future studies on the investigation of the electrochemical response of this type of electrocatalyst in other fields of interest, such as direct alcohol fuel cells in alkaline medium, electrosensing applications, or $\mathrm{CO}_{2}$ electrochemical reductions, are also needed.

\section{Materials and Methods}

\subsection{Materials}

Propargyl alcohol (PGA) was of analytical grade (plus 99\% purity, from Alfa Aesar). PGA was purified through distillation before use and its purity was determined by ${ }^{1} \mathrm{H}$ NMR. The cationic exchange cross-linked, Nafion perfluorinated resin $5 \mathrm{wt} . \%$ in isopropyl/water solution was purchased from Sigma Aldrich. The anion exchange cross-linked, poly(4-vinyl-pyridine) cross-linked, methyl chloride quaternary salt resin (named in this article 4VP, with a molecular weight of ca. $105.10 \mathrm{~g} \mathrm{~mol}^{-1}$, CAS number :125200-80-8) with beads of 300-1000 mm particle size was purchased from Sigma Aldrich. The preparation of $2 \mathrm{wt} . \% 4 \mathrm{VP}$ aqueous solutions was described in [43]. All the chemicals used were of the highest purity available. All solutions were prepared using doubly distilled water with resistivity not less than $18.2 \mathrm{M} \Omega \mathrm{cm}$.

\subsection{Preparation of the Carbons}

Two series of copper-doped carbons were prepared using various precursors and synthetic routes. First, a lignocellulosic precursor (Agave sisalana) was impregnated in a $7 \mathrm{mmol}$ copper carbonate aqueous solution with stirring for $24 \mathrm{~h}$, dried at $100{ }^{\circ} \mathrm{C}$ overnight, and carbonized at $800{ }^{\circ} \mathrm{C}$ for $1 \mathrm{~h}$ in an inert atmosphere. The obtained solid was labeled as SCu. For comparison purposes, the precursor was also activated in potassium carbonate to allow the development of porosity in the absence of copper (sample S). A second material was prepared by carbonization of a mixture of a copper metal organic framework (MOF HKUST-1 [47]) and graphite oxide (GO), as described elsewhere [37,48]. Briefly, GO powder was added to a mixture containing the MOF precursors well dissolved in dimethylformamyde, DMF (ca. $64.7 \mathrm{mg} \mathrm{GO} / \mathrm{mL} \mathrm{DMF}$ ), sonicated for $5 \mathrm{~min}$, and stirred for another $30 \mathrm{~min}$. Afterwards, the suspension was heated at $85^{\circ} \mathrm{C}$ in an oil bath for $21 \mathrm{~h}$ under continuous 
shaking. After cooling, the crystals were filtered, washed in DMF and immersed in dichloromethane for 3 days, and dried at $170{ }^{\circ} \mathrm{C}$ in a vacuum for $28 \mathrm{~h}$. Subsequently, the sample was heated in an inert atmosphere at $800^{\circ} \mathrm{C}\left(100 \mathrm{~mL} / \mathrm{min}\right.$ for $1 \mathrm{~h}$ and $\left.10^{\circ} \mathrm{C} / \mathrm{min}\right)$ and the final black solid was labeled as $\mathrm{CMCuGr}$. The solid obtained by thermal treatment of the metal organic framework in the absence of $\mathrm{GO}$ was also prepared for comparison (sample $\mathrm{CMCu}$ ).

\subsection{Preparation of the Anodes}

Catalytic inks were prepared by mixing copper-doped nanoporous carbons in isopropyl alcohol solution in order to reach a $10 \mathrm{mg} / \mathrm{mL}$ nanoporous carbon concentration and with a percentage of $40 \mathrm{wt} . \%$ and $12 \mathrm{wt} . \%$ for Nafion and 4VP ionomers with respect to the nanoporous carbon weight, respectively. Starting binder solutions were prepared from the $5 \mathrm{wt} . \%$ Nafion and $2 \mathrm{wt} . \% 4 \mathrm{VP}$ aqueous solutions, respectively. Alcoholic dispersions based on the synthesized materials in the presence of either Nafion or $4 \mathrm{VP}$ were sonicated for $30 \mathrm{~min}$ using an ultrasound cleaning bath. Thereafter, the catalytic ink (an accurate $10 \mu \mathrm{L}$ ) was drop-casted on to a polished glassy carbon electrode (GCE, Goodfellow, Huntingdon, UK) with a diameter of $3.0 \mathrm{~mm}$ and dried in an inert atmosphere. Electrodes prepared using either Nafion or $4 \mathrm{VP}$ ionomer are labeled as Nafion/material or $4 \mathrm{VP} /$ material, respectively, e.g., $4 \mathrm{VP} / \mathrm{SCu}$ or Nafion/SCu.

\subsection{Characterization Techniques}

Nitrogen adsorption/desorption isotherms at $-196^{\circ} \mathrm{C}$ were measured in a volumetric analyzer (Micromeritics) on samples previously degassed in a vacuum at $120^{\circ} \mathrm{C}$ for $17 \mathrm{~h}$. Gas data was used to calculate the specific surface area $\left(\mathrm{S}_{\mathrm{BET}}\right)$, total pore volume $\left(\mathrm{V}_{\mathrm{PORES}}\right)$ and micropore volumes $\left(\mathrm{V}_{\mathrm{MIC}}\right)$ using the Dubinin-Radushkevich formulation. Ultra-high purity gases were provided by Air Products. X-ray photoelectronic spectroscopy (XPS) experiments were recorded on a K-Alpha Thermo Scientific spectrometer using AlK $\alpha(1486.6 \mathrm{eV})$ radiation, monochromatized by a twin crystal monochromator and yielding a focused X-ray spot with a diameter of $400 \mathrm{~mm}$, at a current of $3 \mathrm{~mA}$ and a voltage of $12 \mathrm{kV}$. Deconvolution of the XPS spectra was carried out using a Shirley background. High-resolution SEM images were obtained using a field emission scanning electron microscopy (FESEM) (ZEISS model Merlin VP Compact). TEM was performed on a Zeiss EM 902 instrument. The microscope has a line resolution of $0.34 \mathrm{~nm}$ and a point resolution of $0.5 \mathrm{~nm}$ and operates in normal diffraction, and low dose modes at 50 or $80 \mathrm{kV}$. Analyses were performed after the samples were dispersed in ethanol.

\subsection{Electrochemical Characterization}

Cyclic voltammetry (CV) experiments were performed using an Autolab III (Eco Chemie, The Netherlands). The counter electrode (CE) was a gold wire and the reference electrode (RE) was $\mathrm{AgCl} / \mathrm{Ag} /(3.5 \mathrm{M} \mathrm{KCl})$. When the working electrode (WE) consisted of a $\mathrm{Cu}$ rod $(3.0 \mathrm{~mm}$ diameter, from Goodfellow, 99.99 purity), it was pre-treated by abrasive erosion using alumina slurry of 1.0-0.05 $\mu \mathrm{m}$ particle size for $5 \mathrm{~min}$ each one using water as a lubricant. Thereafter, the $\mathrm{Cu}$ rod was sonicated and washed with doubly distilled water. Finally, the WE was immersed in $0.1 \mathrm{M} \mathrm{NaOH}$ solution at open circuit potential followed by cycling the WE at an electrochemical potential range between -0.9 and $+0.9 \mathrm{~V}$ at $10 \mathrm{mV} \mathrm{s}^{-1}$ using a three-electrode glass electrochemical cell. CVs were performed in the absence and presence of $0.02 \mathrm{M}$ PGA as a reference concentration. In the case of using copper-based carbon materials as the WE, catalytic inks of the materials dispersed in isopropyl alcohol (ca. $10 \mathrm{mg} / \mathrm{mL}$ ) were drop cast on a glassy carbon electrode (GCE) and explored under the same experimental conditions as described above. Measurements were carried out at $293 \pm 2 \mathrm{~K}$ and in an argon atmosphere.

\section{Conclusions}

Copper-carbon composites prepared from various carbon precursors were used as electroactive materials for the electrooxidation of propargyl alcohol in an alkaline medium. The PGA 
electrooxidation response was found to be very dependent on the nature of the carbon matrix, copper loading, and the nature of the ionomer used for the preparation of the catalytic ink. In this sense, the copper-based nanocarbon-to-ionomer ratio turned out to be crucial for balancing the catalytic efficiency and mechanical properties of the copper-doped nanoporous carbon electrodes. While $40 \mathrm{wt} . \%$ Nafion in the catalyst inks was sufficient for good particle cohesion and electrochemical behavior of the copper-doped nanoporous carbons, a $12 \mathrm{wt}$ \% anionic ionomer 4VP was found to be optimal in terms of catalytic activity and the mechanical property of the electrode film. The use of the anionic ionomer in the catalytic inks resulted in the loss of the copper electroactive area as a consequence of the possible blockage of the active area due to high interaction between copper particles and nitrogen atoms from the $4 \mathrm{VP}$ ionomer. Besides, both chemical composition and structure of the anionic resin could lead to the covering of carbon porosity in addition to the fouling of the metal surface, hiding alcohol molecule transport through the active area and its consequent electrooxidation. Conversely, Nafion cationic resin barely had a negative effect on the electrochemical behavior of copper electrocatalysts in the redox reactions of different copper species and PGA electrooxidation.

Supplementary Materials: The following are available online at http://www.mdpi.com/2311-5629/3/4/36/s1: Figure S1: XPS spectra of the main $\mathrm{Cu} 2 \mathrm{p} 3 / 2$ signal for all samples, Figure S2: Representative TEM images, Figure S3: Cyclic voltammograms of the electrochemical response of undoped S carbon.

Acknowledgments: This work was partially funded by the Spanish Ministerio de Economía y Competitividad (MINECO) (grants CTQ2013-48280-C3-3-R, CTQ2016-76231-C2-2-R) and European Council Research through a Consolidator Grant (ERC-CoG-648161-PHOROSOL).

Author Contributions: All authors contributed equally in the conception and design of the experiments, and discussion of the obtained results; Leticia García-Cruz and Conchi O. Ania performed the experiments; Leticia García-Cruz, Conchi O. Ania, Jesús Iniesta, Vicente Montiel, Teresa J. Bandosz and Ana Paula Carvalho analyzed the data; and Leticia García-Cruz, Jesús Iniesta and Conchi O. Ania wrote the paper.

Conflicts of Interest: The authors declare no conflict of interest.

\section{References}

1. Zou, X.X.; Zhang, Y. Noble metal-free hydrogen evolution catalysts for water splitting. Chem. Soc. Rev. 2015, 44, 5148-5180. [CrossRef] [PubMed]

2. Higgins, D.; Zamani, P.; Yu, A.P.; Chen, Z.W. The application of graphene and its composites in oxygen reduction electrocatalysis: A perspective and review of recent progress. Energy Environ. Sci. 2016, 9, 357-390. [CrossRef]

3. Lee, D.U.; Xu, P.; Cano, Z.P.; Kashkooli, A.G.; Park, M.G.; Chen, Z.W. Recent progress and perspectives on bi-functional oxygen electrocatalysts for advanced rechargeable metal-air batteries. J. Mater. Chem. A 2016, 4 , 7107-7134. [CrossRef]

4. Chen, Z.W.; Higgins, D.; Yu, A.P.; Zhang, L.; Zhang, J.J. A review on non-precious metal electrocatalysts for pem fuel cells. Energy Environ. Sci. 2011, 4, 3167-3192. [CrossRef]

5. Ozoemena, K.I. Nanostructured platinum-free electrocatalysts in alkaline direct alcohol fuel cells: Catalyst design, principles and applications. RSC Adv. 2016, 6, 89523-89550. [CrossRef]

6. Giri, S.D.; Sarkar, A. Electrochemical study of bulk and monolayer copper in alkaline solution. J. Electrochem. Soc. 2016, 163, I1252-I1259. [CrossRef]

7. Miller, B. Split-ring disk study of anodic processes at a copper electrode in alkaline solution. J. Electrochem. Soc. 1969, 116, 1675-1680. [CrossRef]

8. Dechialvo, M.R.G.; Marchiano, S.L.; Arvia, A.J. The mechanism of oxidation of copper in alkaline-solutions. J. Appl. Electrochem. 1984, 14, 165-175. [CrossRef]

9. Ambrose, J.; Barradas, R.G.; Shoesmit, D.W. Rotating copper disk electrode studies of mechanism of dissolution-passivation step on copper in alkaline solutions. J. Electroanal. Chem. 1973, 47, 65-80. [CrossRef]

10. Ambrose, J.; Shoesmit, D.W. Investigations of copper in aqueous alkaline solutions by cyclic voltammetry. J. Electroanal. Chem. 1973, 47, 47-64. [CrossRef]

11. $\mathrm{Hu}, \mathrm{X}$.; Wang, J. A simple route of modifying copper electrodes for the determination of methanol and ethylene glycol. Electroanalysis 2012, 24, 1639-1645. [CrossRef] 
12. Luo, M.Z.; Baldwin, R.P. Characterization of carbohydrate oxidation at copper electrodes. J. Electroanal. Chem. 1995, 387, 87-94. [CrossRef]

13. Gao, X.H.; Du, C.; Zhang, C.M.; Chen, W. Copper nanoclusters on carbon supports for the electrochemical oxidation and detection of hydrazine. ChemElectroChem 2016, 3, 1266-1272. [CrossRef]

14. Priya, S.; Berchmans, S. Cuo microspheres modified glassy carbon electrodes as sensor materials and fuel cell catalysts. J. Electrochem. Soc. 2012, 159, F73-F80. [CrossRef]

15. Hasanzadeh, M.; Karim-Nezhad, G.; Mahjani, M.G.; Jafarian, M.; Shadjou, N.; Khalilzadeh, B.; Saghatforoush, L.A. A study of the electrocatalytic oxidation of cyclohexanol on copper electrode. Catal. Commun. 2008, 10, 295-299. [CrossRef]

16. Hasanzadeh, M.; Shadjou, N.; Saghatforoush, L.; Khalilzadeh, B.; Kazeman, I. Electro-oxidation of cyclohexanol on a copper electrode modified by copper-dimethylglyoxime complex formed by electrochemical synthesis. Bull. Korean Chem. Soc. 2009, 30, 2943-2948. [CrossRef]

17. Heli, H.; Jafarian, M.; Mahjani, M.G.; Gobal, F. Electro-oxidation of methanol on copper in alkaline solution. Electrochim. Acta 2004, 49, 4999-5006. [CrossRef]

18. Martin, C.; Huser, H.; Servat, K.; Kokoh, K.B. Electrosynthesis of lactic acid on copper and lead cathodes in aqueous media. Electrochim. Acta 2005, 51, 111-117. [CrossRef]

19. Li, T.T.; Cao, S.; Yang, C.; Chen, Y.; Lv, X.J.; Fu, W.F. Electrochemical water oxidation by in situ-generated copper oxide film from cu(teoa) $\left(\mathrm{H}_{2} \mathrm{O}\right)(2) \mathrm{SO}_{4}$ complex. Inorg. Chem. 2015, 54, 3061-3067. [CrossRef] [PubMed]

20. Liu, X.; Zheng, H.F.; Sun, Z.J.; Han, A.; Du, P.W. Earth-abundant copper-based bifunctional electrocatalyst for both catalytic hydrogen production and water oxidation. ACS Catal. 2015, 5, 1530-1538. [CrossRef]

21. Liu, X.; Cui, S.S.; Sun, Z.J.; Du, P.W. Robust and highly active copper-based electrocatalyst for hydrogen production at low overpotential in neutral water. Chem. Commun. 2015, 51, 12954-12957. [CrossRef] [PubMed]

22. Gattrell, M.; Gupta, N.; Co, A. A review of the aqueous electrochemical reduction of CO2 to hydrocarbons at copper. J. Electroanal. Chem. 2006, 594, 1-19. [CrossRef]

23. Gattrell, M.; Gupta, N.; Co, A. Electrochemical reduction of $\mathrm{co} 2$ to hydrocarbons to store renewable electrical energy and upgrade biogas. Energy Convers. Manag. 2007, 48, 1255-1265. [CrossRef]

24. Kas, R.; Kortlever, R.; Milbrat, A.; Koper, M.T.M.; Mul, G.; Baltrusaitis, J. Electrochemical CO2 reduction on $\mathrm{Cu} 2 \mathrm{o}$-derived copper nanoparticles: Controlling the catalytic selectivity of hydrocarbons. Phys. Chem. Chem. Phys. 2014, 16, 12194-12201. [CrossRef] [PubMed]

25. Malik, M.I.; Malaibari, Z.O.; Atieh, M.; Abussaud, B. Electrochemical reduction of CO2 to methanol over mwcnts impregnated with Cu2o. Chem. Eng. Sci. 2016, 152, 468-477. [CrossRef]

26. Jia, F.L.; Yu, X.X.; Zhang, L.Z. Enhanced selectivity for the electrochemical reduction of co2 to alcohols in aqueous solution with nanostructured cu-au alloy as catalyst. J. Power Sources 2014, 252, 85-89. [CrossRef]

27. Hori, Y.; Takahashi, I.; Koga, O.; Hoshi, N. Selective formation of C2 compounds from electrochemical reduction of $\mathrm{co} 2$ at a series of copper single crystal electrodes. J. Phys. Chem. B 2002, 106, 15-17. [CrossRef]

28. Varela, A.S.; Kroschel, M.; Reier, T.; Strasser, P. Controlling the selectivity of CO2 electroreduction on copper: The effect of the electrolyte concentration and the importance of the local ph. Catal. Today 2016, 260, 8-13. [CrossRef]

29. Reske, R.; Mistry, H.; Behafarid, F.; Roldan Cuenya, B.; Strasser, P. Particle size effects in the catalytic electroreduction of co2 on cu nanoparticles. J. Am. Chem. Soc. 2014, 136, 6978-6986. [CrossRef] [PubMed]

30. Xie, Y.Q.; Huber, C.O. Electrocatalysis and amperometric detection using an electrode made of copper-oxide and carbon paste. Anal. Chem. 1991, 63, 1714-1719. [CrossRef]

31. Jafarian, M.; Avei, M.R.; Danaee, I.; Gobal, F.; Mahjani, M.G. Electrochemical oxidation of saccharose on copper (hydr)oxide-modified electrode in alkaline media. Chin. J. Catal. 2010, 31, 1351-1357. [CrossRef]

32. Rosalbino, F.; Carlini, R.; Soggia, F.; Zanicchi, G.; Scavino, G. Influence of rare earth metals addition on the corrosion behaviour of copper in alkaline environment. Corros. Sci. 2012, 58, 139-144. [CrossRef]

33. Barakat, N.A.M.; El-Newehy, M.; Al-Deyab, S.S.; Kim, H.Y. Cobalt/copper-decorated carbon nanofibers as novel non-precious electrocatalyst for methanol electrooxidation. Nanoscale Res. Lett. 2014, 9, 2. [CrossRef] [PubMed] 
34. Koo, Y.; Malik, R.; Alvarez, N.; White, L.; Shanov, V.N.; Schulz, M.; Collins, B.; Sankar, J.; Yun, Y. Aligned carbon nanotube/copper sheets: A new electrocatalyst for co2 reduction to hydrocarbons. RSC Adv. 2014, 4, 16362-16367. [CrossRef]

35. Liu, C.B.; Zhang, H.; Tang, Y.H.; Luo, S.L. Controllable growth of graphene/cu composite and its nanoarchitecture-dependent electrocatalytic activity to hydrazine oxidation. J. Mater. Chem. A 2014, 2, 4580-4587. [CrossRef]

36. Heli, H.; Jabbari, A.; Zarghan, M.; Moosavi-Movahedi, A.A. Copper nanoparticles-carbon microparticles nanocomposite for electrooxidation and sensitive detection of sotalol. Sens. Actuators B Chem. 2009, 140, 245-251. [CrossRef]

37. Ania, C.O.; Seredych, M.; Rodriguez-Castellon, E.; Bandosz, T.J. New copper/go based material as an efficient oxygen reduction catalyst in an alkaline medium: The role of unique cu/rgo architecture. Appl. Catal. B Environ. 2015, 163, 424-435. [CrossRef]

38. Garcia-Cruz, L.; Saez, A.; Ania, C.O.; Solla-Gullon, J.; Thiemann, T.; Iniesta, J.; Montiel, V. Electrocatalytic activity of ni-doped nanoporous carbons in the electrooxidation of propargyl alcohol. Carbon 2014, 73, 291-302. [CrossRef]

39. Yan, X.Y.; Tong, X.L.; Zhang, Y.F.; Han, X.D.; Wang, Y.Y.; Jin, G.Q.; Qin, Y.; Guo, X.Y. Cuprous oxide nanoparticles dispersed on reduced graphene oxide as an efficient electrocatalyst for oxygen reduction reaction. Chem. Commun. 2012, 48, 1892-1894. [CrossRef] [PubMed]

40. Antolini, E.; Gonzalez, E.R. Alkaline direct alcohol fuel cells. J. Power Sources 2010, 195, 3431-3450. [CrossRef]

41. El Din, A.M.S.; El Wahab, F.M.A. The behaviour of the copper electrode in alkaline solutions upon alternate anodic and cathodic polarization. Electrochim. Acta 1964, 9, 113-121. [CrossRef]

42. Lorimer, J.P.; Mason, T.J.; Plattes, M.; Walton, D.J. Passivation phenomena during sonovoltammetric studies on copper in strongly alkaline solutions. J. Electroanal. Chem. 2004, 568, 379-390. [CrossRef]

43. Marsh, H.; RodriguezReinoso, F. Activated Carbon; Elsevier Science Bv: Amsterdam, The Netherlands, 2006; pp. 1-536.

44. Garcia-Cruz, L.; Iniesta, J.; Thiemann, T.; Montiel, V. Surprising electrooxidation of propargyl alcohol to (z)-3-(2-propynoxy)-2-propenoic acid at a niooh electrode in alkaline medium. Electrochem. Commun. 2012, 22, 200-202. [CrossRef]

45. Matsuoka, K.; Iriyama, Y.; Abe, T.; Matsuoka, M.; Ogumi, Z. Alkaline direct alcohol fuel cells using an anion exchange membrane. J. Power Sources 2005, 150, 27-31. [CrossRef]

46. Garcia-Cruz, L.; Casado-Coterillo, C.; Irabien, A.; Montiel, V.; Iniesta, J. Performance assessment of a polymer electrolyte membrane electrochemical reactor under alkaline conditions-A case study with the electrooxidation of alcohols. Electrochim. Acta 2016, 206, 165-175. [CrossRef]

47. Chui, S.S.Y.; Lo, S.M.F.; Charmant, J.P.H.; Orpen, A.G.; Williams, I.D. A chemically functionalizable nanoporous material Cu-3(tma)(2)( $\left.\mathrm{H}_{2} \mathrm{O}\right)(3)$ (n). Science 1999, 283, 1148-1150. [CrossRef] [PubMed]

48. Petit, C.; Burress, J.; Bandosz, T.J. The synthesis and characterization of copper-based metal-organic framework/graphite oxide composites. Carbon 2011, 49, 563-572. [CrossRef]

(C) 2017 by the authors. Licensee MDPI, Basel, Switzerland. This article is an open access article distributed under the terms and conditions of the Creative Commons Attribution (CC BY) license (http:// creativecommons.org/licenses/by/4.0/). 